P54 IMPROVING DOMICILIARY END OF LIFE CARE THROUGH THE DEVELOPMENT AND EVALUATION OF A SPECIALISED PROGRAMME FOR DOMICILIARY CARE ORGANISATIONS

Lynne Partington. Cheshire Hospices Education, Winsford, UK, Merseyside and Cheshire Clinical Network, Greater Manchester, Lancashire \& South Cumbria Strategic Clinical Network \& Senate

\subsection{6/bmjspcare-2013-000591.76}

Background/Context Within the UK, there is a drive to reduce the number of hospital deaths thus potentially increasing end of life care in the community. However, there has not been a corresponding increase in the numbers of professional health care workers, so organisations such as domiciliary care agencies are providing more complex care and support for very ill patients in their own homes. This is an emerging role for these organisations so they need development, education and support to provide quality end of life care.

Aim The 'Six Steps to Success' programme was originally developed to enable nursing homes to implement a structured organisational change to enable the delivery of the best end of life care. The programme has been adapted for use with domiciliary care agencies, involving a multi agency approach to developing the programme.

Approach used

A pilot programme with four different organisations was pioneered, with the organisations participating both as learning organisations and evaluation partners. The pilot programme was evaluated both pre and post programme using three tools: Quality Markers, Post Death Information (PDI) and a Knowledge, Skills and Confidence audit.

Outcomes The results have established an increase in the quality of end of life care through a number of means, ranging from early identification of patients at the end of life through to improved communications with other agencies. Qualitative data has also been captured which demonstrates real life impacts and changes.

Application to Practice Supporting domiciliary agencies to care for the increasing number of patients requiring end of life care in their own homes has often been provided by hospices and their education departments. However, education alone is often not enough to make the changes required within an organisation and this programme can influence more extensive changes through a structured and systematic approach.

\section{P55 PALLIATIVE CARE MASTER CLASS SERIES FOR GP'S}

Debbie Ho, Dr Kate Tredgett, Jill Beckhelling. Prospect Hospice, Swindon, UK

\subsection{6/bmjspcare-2013-000591.77}

Introduction A key strategic priority for the Hospice is extending the reach of its influence to more people facing the end of life. Key to this is its collaboration with GPs across its community. Following a needs assessment, an alignment with the local Education Trust (SET) was formed and a bespoke Master Class Series for GP's developed. SET is the local coordinator and communicator of education for 170 GP members.

Aims Year 1: 30\% GPs to attend at least 1 session and 10\% to attend 2 or more.

Over 3 year period for $70 \%$ GPs to attend at least 1 session and $40 \%$ to attend 2 or more.
Method A rolling programme of three 2 hour educational sessions commenced in 2012:

1. Amitriptyline to Zomorph via Oxycodone and beyond' - Successful pain management in palliative care

2. 'Managing your 1\%' - How to optimise care for your patients in the last year of life including advance care planning, DNAR, and services available to support GP's.

3. 'Achieving a successful home death' - The 'how to' guide for general practitioners including syringe driver conversions, just in case medications, ethical dilemmas and services available

Sessions were designed to be cumulative with concepts revisited and developed to reinforce learning. Case based and interactive, sessions provided opportunities for sharing experience, questions and reflection. Sessions ran on several occasions, and were free of charge.

Results Sessions were evaluated using a 'reaction' feedback form. Two months after the course GPs were sent a structured impact assessment form on which to provide an account of one occasion when they have applied the knowledge acquired during the course. Completing part 2 of the evaluation extended CPD credits from 2 to 4 per session.

The target attendance for year 1 has been exceeded and evaluation by GPs has been excellent.

\section{P56 RECORDING VOICES. WHY IS ORAL HISTORY IMPORTANT IN PALLIATIVE CARE AND BEREAVEMENT?}

${ }^{1}$ Michelle Winslow, ${ }^{1}$ Sam Smith, ${ }^{2}$ Adrienne Betteley, ${ }^{1}$ Bill Noble. 'University of Sheffield, ${ }^{2}$ Macmillan Cancer Support

\subsection{6/bmjspcare-2013-000591.78}

Oral history is the recording of unique life experience; it captures and preserves voices and participants are involved in the process of producing their own life histories. An oral history service for patients has run successfully in the Sheffield Macmillan Unit for Palliative Care since 2007. In 2012, with Macmillan Cancer Support we embarked on a project to develop oral history in pilot sites in the north of England and Northern Ireland. Evaluation of these services will determine whether oral history as a service will be rolled out nationally.

Oral history complements palliative care services, it offers time to reflect, record identity and make a family record in the teller's voice. A motivation for recording life stories can be the opportunity to create a family record. Oral history interviews are carried out by trained volunteers. Participants receive an audio $\mathrm{CD}$ soon after their interview and recordings are securely archived. With consent, interviews are available for research.

To understand the role of oral history in palliative care and bereavement, a further 12 month project is assessing the impact of creating an oral history. We have analysed an existing archive of 200 oral histories and sought views from participants, family and friends via semi structured interviews and a questionnaire. Results are contributing important insights into the meaning of oral history for people who make recordings, and for those who receive them.

Findings from both projects offer vital academic information to support the future shape and direction of Macmillan oral history services. We are establishing that oral history enhances patient experience of palliative care by providing opportunities to reflect and express identity in a non-medical context. 